\title{
Envoplakin and Periplakin Are the Paraneoplastic Pemphigus Antigens
}

\author{
CHIE KIYOKAWA \\ Department of Dermatology, Kurume University School of Medicine, \\ Kurume 830-0011, Japan
}

\begin{abstract}
Summary: Paraneoplastic pemphigus (PNP) sera have been reported to immunoprecipitate multiple proteins, including the $250 \mathrm{kDa}$ and $210 \mathrm{kDa}$ proteins believed to correspond to desmoplakins I/II, BP230, and two unidentified proteins of $190 \mathrm{kDa}$ and $170 \mathrm{kDa}$. We have recently provided evidence that the presence of the $210 \mathrm{kDa}$ and $190 \mathrm{kDa}$ proteins is the most prominent feature of PNP, and have suggested that the major $210 \mathrm{kDa}$ antigen may not correspond to desmoplakin II. Using immunoprecipitation and immunoblotting, we found that some PNP sera identified a doublet protein migrating at $210 \mathrm{kDa}$, with the larger protein corresponding to desmoplakin II, and the smaller protein corresponding to envoplakin, a recently described precursor of the keratinocyte cornified envelope. In contrast to desmoplakin II, envoplakin was detected by all PNP sera analyzed. Using immunoblotting and immunoprecipitation, we further showed that the $190 \mathrm{kDa}$ PNP antigen is identical to periplakin, another recently identified envelope precursor that can form complexes with envoplakin. Like desmoplakin and BP230, envoplakin and periplakin belong to the plakin family of proteins.
\end{abstract}

Key words desmosome, immunoblot, immunoprecipitation, plakin

\section{INTRODUCTION}

Indirect immunofluorescence has shown that in skin blistering diseases of the pemphigus type, autoantibodies are specifically directed against the cell surface of epidermal keratinocytes [1,2]. Immunochemical studies have identified the $130 \mathrm{kDa}$ pemphigus vulgaris antigen (desmoglein 3, or Dsg3) and the $160 \mathrm{kDa}$ pemphigus foliaceus antigen (Dsg1) [1,3-6].

Paraneoplastic pemphigus (PNP) is a relatively recently reported autoimmune blistering disease, characterized by mucosal erosions and skin lesions associated with neoplasia, particularly malignant ymphoma [7-9]. Since the initial description of the disease, other investigators have reported similar cases [10-16]. Although pemphigus vulgaris and pemphigus foliaceus sera react exclusively with the cell surface of the epidermis, PNP sera have been shown to bind in addition to non-stratified epithelia of other tissues. Furthermore, while pemphigus vulgaris and pemphigus foliaceus autoantibodies which primarily recognize single members of the desmoglein family, PNP antibodies immunoprecipitate a complex profile of multiple antigens, migrating at $250 \mathrm{kDa}, 230 \mathrm{kDa}, 210 \mathrm{kDa}, 190 \mathrm{kDa}$ and $170 \mathrm{kDa}$. It has been suggested that the $250 \mathrm{kDa}$ and $210 \mathrm{kDa}$ proteins are desmoplakins I/II, and the $230 \mathrm{kDa}$ protein is the $230 \mathrm{kDa}$ bullous pemphigoid antigen (or BP230) [7,9], but the nature of the $190 \mathrm{kDa}$ and $170 \mathrm{kDa}$ proteins has not yet been investigated.

Using immunoblotting, we have previously shown that all PNP sera detect a characteristic $210 \mathrm{kDa}$ and $190 \mathrm{kDa}$ doublet by immunoblotting of extracts of normal human epidermis [17]. Although earlier studies reported that the $210 \mathrm{kDa}$ protein represents desmoplakin II, our immunoblot analysis suggested that at least one other autoantigen was present in this molecular weight range. The mobility of the $210 \mathrm{kDa}$ protein band recognized most prominently on immunoblotting by PNP sera was greater than that of desmoplakin II [17]. Furthermore, 
PNP sera that did not recognize desmoplakin I by immunoblotting did show reactivity with a $210 \mathrm{kDa}$ protein [17]. In these cases, it seems unlikely that the $210 \mathrm{kDa}$ protein represents desmoplakin II, based on the fact that the vast majority of antibodies recognizing desmoplakin II should also recognize desmoplakin I, as the desmoplakin II coding sequence is entirely contained within the larger desmoplakin message that gives rise to both forms of the molecule by alternative splicing [18].

Recent studies have identified a number of novel molecules related to cornified envelope formation. The cornified envelope is a layer of insoluble proteins, deposited on the inner surface of the plasma membrane of keratinocytes in the cornified layer of the epidermis [19-21]. The envelope is a product of several precursor proteins, including involucrin and loricrin, that are cross-linked by epidermal transglutaminases [23-25]. In 1984, Simon and Green identified two membrane-associated proteins with apparent molecular weights of $195 \mathrm{kDa}$ and $210 \mathrm{kDa}$ that are cross-linked upon transglutaminase activation [25]. The molecular cloning and characterization of these two proteins, named envoplakin and periplakin, has revealed that they belong to the plakin family of proteins, which also includes desmoplakin I/II, BP230 and plectin [27-29]. In addition, envoplakin and periplakin are considered to bind to each other by uncovalent bond [29].

In epidermal keratinocytes, envoplakin and periplakin partially co-localize with desmoplakin at desmosomal plagues and on keratin filaments, suggesting that they may play a role in connecting keratin filaments to desmosomes [28,29]. It is speculated that a network of desmoplakin, envoplakin and periplakin may provide a scaffolding upon which the cornified envelope is assembled, and that these proteins may anchor desmosomes and keratin filaments to the cornified envelope [29]. Interestingly, expression of envoplakin and periplakin is not restricted to stratified squamous epithelia.

These previous observations led us to speculate that the $210 \mathrm{kDa}$ and $190 \mathrm{kDa}$ PNP antigens may be related to envoplakin and periplakin, respectively. In fact, Kim et al. (1997) have recently reported that by immunoscreening a keratinocyte cDNA library with a PNP serum they cloned a partial cDNA corresponding to envoplakin, which strongly suggests that the $210 \mathrm{kDa}$ protein is envoplakin [30]. In the present study, using polyclonal antibodies specific to envoplakin and periplakin and sera of PNP patients for immunoblotting and immunoprecipitation, we demonstrated that envoplakin and periplakin are identical to the $210 \mathrm{kDa}$ and the $190 \mathrm{kDa}$ PNP antigens.

\section{MATERIALS AND METHODS}

\section{Sera}

Sera were obtained from 6 new PNP patients, 8 pemphigus vulgaris patients, a bullous pemphigoid patient and 2 normal volunteers. The 6 PNP sera used in the immunoblotting and immunoprecipitation-immunoblotting experiments described below. In standard immunoprecipitation of radiolabeled keratinocytes, additional 4 U.S. PNP sera were used.

All the sera were stored at $-30{ }^{\circ} \mathrm{C}$ or at $4{ }^{\circ} \mathrm{C}$ in the presence of $0.1 \% \mathrm{NaN}_{3}$. An anti-desmoplakin mouse monoclonal antibody (11-5F) was a generous gift from Dr. David R. Garrod, Manchester University, Manchester, U.K. Rabbit polyclonal antibodies against envoplakin (CR1 and CR5) and periplakin (CR3) were generous gift from Dr. Chritiana Ruhrberg and Dr. Fiona M. Watt, Keratinocyte Laboratory, London, U.K. and these were previously characterized $[28,29]$.

\section{Immunoblot analysis}

Immunoblot analysis of extracts of EDTA-separated normal human epidermis using 6\% SDSPAGE gel under reducing condition was performed by the same method described previously $[3,17,31]$. Color was developed using 4-chloro-1-naphthol in the presence of $\mathrm{H}_{2} \mathrm{O}_{2}$.

\section{Immunoprecipitation using extracts of radiolabeled keratinocytes}

Standard immunoprecipitation was performed according to the previously described technique [7], using cultured normal human keratinocytes which were radiolabeled with $\left[{ }^{14} \mathrm{C}\right]$ amino acids and extracted with extraction buffer containing $0.5 \%$ NP40. Samples were immunoprecipitated with PNP sera or the CR1 antibody specific for envoplakin.

\section{Combination of immunoblotting and immunopre- cipitation}

To examine the relationship between envoplakin, periplakin and the PNP antigens, two different methods for immunoblotting of immunoprecipitated proteins were used.

Firstly, the reactivity of PNP patients' sera with proteins immunoprecipitated by antibodies specific 
for desmoplakin (11-5F), envoplakin (CR1) or periplakin (CR3) was examined. In this experiment, protein extracts of normal human epidermal keratinocyte cultures were immunoprecipitated, separated on $6 \%$ SDS-PAGE gels and transferred to nitrocellulose membranes as described previously [28]. The membrane was successively incubated with PNP sera and horseradish peroxidase-conjugated anti-human IgG antibody (DAKO, Copenhagen, Denmark), and positive bands were detected by ECL (Amersham International plc, Buckinghamshere, U.K.). In some experiments, after stripping in 62.5 $\mathrm{mM}$ Tris-buffer ( $\mathrm{pH}$ 6.8) containing 2\% SDS and $100 \mathrm{mM}$ beta-mercaptoethanol at $50{ }^{\circ} \mathrm{C}$ for $30 \mathrm{~min}$, the membrane was re-probed with pemphigus vulgaris or normal sera as negative controls.

In a reciprocal experiment, we examined the reactivity of antibodies specific for envoplakin and periplakin with proteins immunoprecipitated by PNP sera. In this experiment, we modified a previously described method [32]. We used normal human epidermal extracts in 1.5\% SDS-Tris buffer, a standard sample used for our immunoblotting [3,17,31], as an antigen source. The epidermal extracts were diluted 20 -fold with $0.5 \%$ Triton X-100 in Tris-buffered saline to reduce the SDS concentration to $0.075 \%$. Subsequent immunoprecipitation was performed as previously described [32]. Immunoprecipitates were extensively washed and boiled in Laemmli's sample buffer containing $5 \%$ beta-mercaptoethanol. The released proteins were separated on $4-20 \%$ gradient gels under reducing condition and transferred to nitrocellulose membranes. Immunoblotting was performed by the method described above, and color was developed using 4-chloro-1-naphthol.

\section{RESULTS}

Envoplakin and periplakin have the same electrophoretic mobility as the $210 \mathrm{kDa}$ and $190 \mathrm{kDa}$ $P N P$ antigens on immunoblots of epidermal extracts

Immunoblotting of epidermal extracts revealed that all the 6 PNP sera reacted with the previously reported proteins migrating at $210 \mathrm{kDa}$ and $190 \mathrm{kDa}$; however, the relative abundance of the two protein bands appeared to vary between individual patient sera [17] (Fig. 1; lanes 2, 3 and data not shown).

In comparison, a pemphigus vulgaris serum reacted with Dsg1 and Dsg3 and a bullous pemphigoid serum reacted with the BP230 and $180 \mathrm{kDa}$ bullous pemphigoid antigens (or BP180), while 2 normal sera showed no specific reactivity (data not shown).

In order to begin to investigate the relationship between these antigens and the recently described envoplakin and periplakin, we compared the mobility of the protein bands recognized by the PNP sera with those recognized by antibodies specifically directed against either envoplakin (CR1 and CR5) (lane 4 and data not shown) or periplakin (CR3) (lane 5). These antibodies recognized protein bands of the same electrophoretic mobility as the $210 \mathrm{kDa}$ and $190 \mathrm{kDa}$ PNP antigens (lanes 2 and 3), raising the possibility that the PNP sera may be recognizing envoplakin and periplakin. Previously, a $210 \mathrm{kDa}$ protein recognized by PNP sera was reported to be desmoplakin II, and we show here that at least one of the PNP sera (lane 3 ) does indeed recognize protein bands of the same
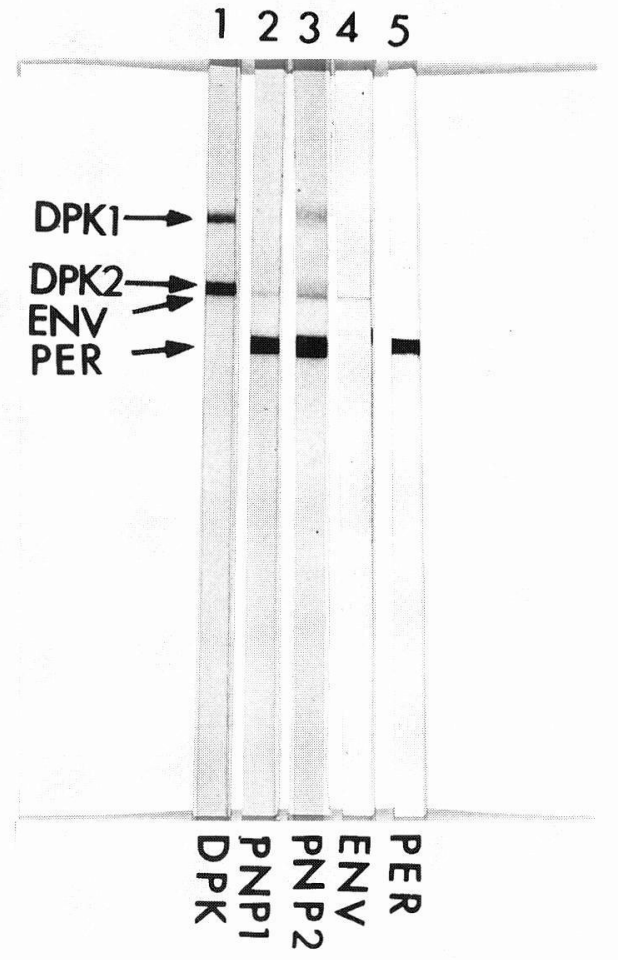

Fig. 1. Envoplakin and periplakin have the same electrophoretic mobility as the $210 \mathrm{kDa}$ and $190 \mathrm{kDa}$ PNP antigens. By immunoblotting of epidermal extracts using 6\% SDS-PAGE gel, an anti-desmoplakin antibody reacted with the 250 $\mathrm{kDa}$ and $210 \mathrm{kDa}$ desmoplakins I/II (lane 1). Two PNP sera examined reacted with the $210 \mathrm{kDa}$ and $190 \mathrm{kDa}$ doublet proteins (lanes 2 and 3). An antienvoplakin antibody (lane 4) detected a protein band with the same mobility as the $210 \mathrm{kDa}$ PNP antigen, which migrated slightly faster than desmoplakin II. An anti-periplakin antibody (lane 5) reacted with a protein with the same mobility as the $190 \mathrm{kDa}$ PNP antigen. 
molecular weight as both desmoplakins I/II detected by anti-desmoplakin antibody on immunoblots (lane 1). However, while desmoplakin II actually migrates somewhat more slowly than envoplakin (compare lanes 1 and 4 in Fig. 1), this figure illustrates the difficulty in determining based on molecular weight alone what species are actually presented at the 210 $\mathrm{kDa}$ region of the lanes reacted with PNP sera.

Immunoprecipitation of metabolically labeled keratinocytes with the $P N P$ sera and anti-envoplakin antibody provided further support for the observations by immunoblotting

As expected, all previously described components of the PNP antigen complex were detected, i.e., the $250 \mathrm{kDa}, 230 \mathrm{kDa}, 210 \mathrm{kDa}, 190 \mathrm{kDa}$, and 170 kDa proteins (Fig. 2; lanes 2 and 3), and the electrophoretic mobility of the immunoprecipitated 210 $\mathrm{kDa}$ and $190 \mathrm{kDa}$ PNP antigens were identical to

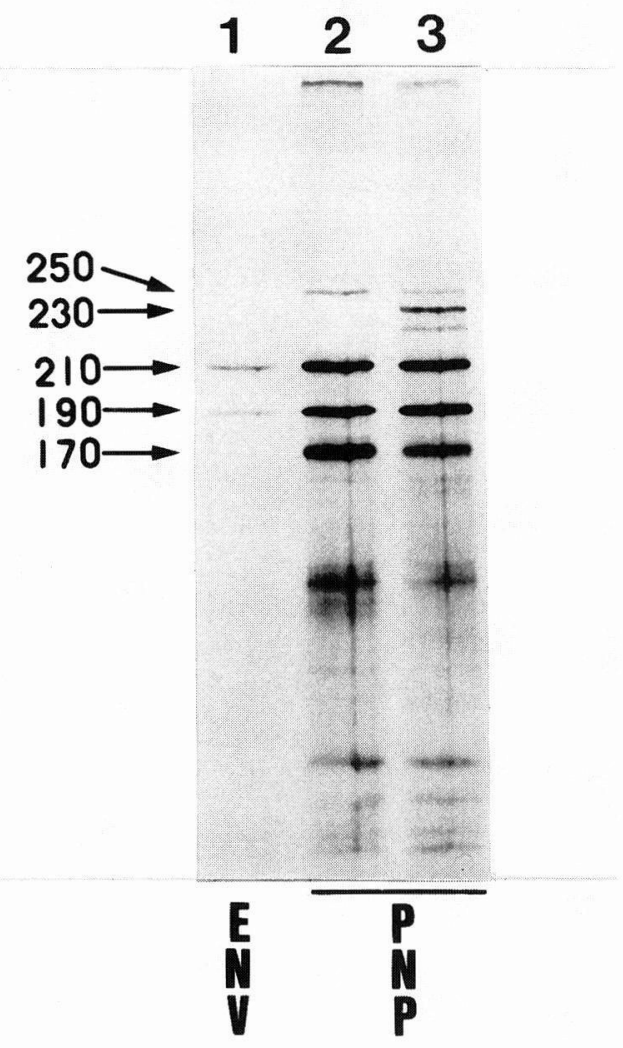

Fig. 2. Immunoprecipitation using metabolically radiolabeled keratinocytes indicates that envoplakin and periplakin co-migrate with the 210 $\mathrm{kDa}$ and $190 \mathrm{kDa}$ PNP antigens. Two PNP sera immunoprecipitated the $250 \mathrm{kDa}, 230 \mathrm{kDa}, 210$ $\mathrm{kDa}, 190 \mathrm{kDa}$, and $170 \mathrm{kDa}$ proteins (lanes 2 and 3). An anti-envoplakin antibody (CR1) immunoprecipitated two proteins showing the same mobility as the $210 \mathrm{kDa}$ and $190 \mathrm{kDa}$ PNP antigens (lane 1). those of envoplakin and periplakin, which were coimmunoprecipitated with an antibody specific for envoplakin (lane 1), as described previously [29].

Careful examination of PNP immunoprecipitates revealed that the $210 \mathrm{kDa}$ protein was in fact a doublet (Fig. 3), with the upper and lower protein bands showing the same mobility as desmoplakin II and envoplakin, respectively (Fig. 3, and data not shown).

Combination of immunoblotting and immunoprecipitation confirms that envoplakin and periplakin are identical to the $210 \mathrm{kDa}$ and $190 \mathrm{kDa} P N P$ antigens

In order to directly address whether envoplakin and periplakin are identical to the $210 \mathrm{kDa}$ and 190 kDa PNP antigens, keratinocyte extracts were first immunoprecipitated with antibodies specific to desmoplakin, envoplakin and periplakin, and then immunoblotted with the 6 PNP sera. This experiment was kindly performed by Dr. Chritiana Ruhrberg and Dr. Fiona M. Watt, Keratinocyte Laboratory, London,

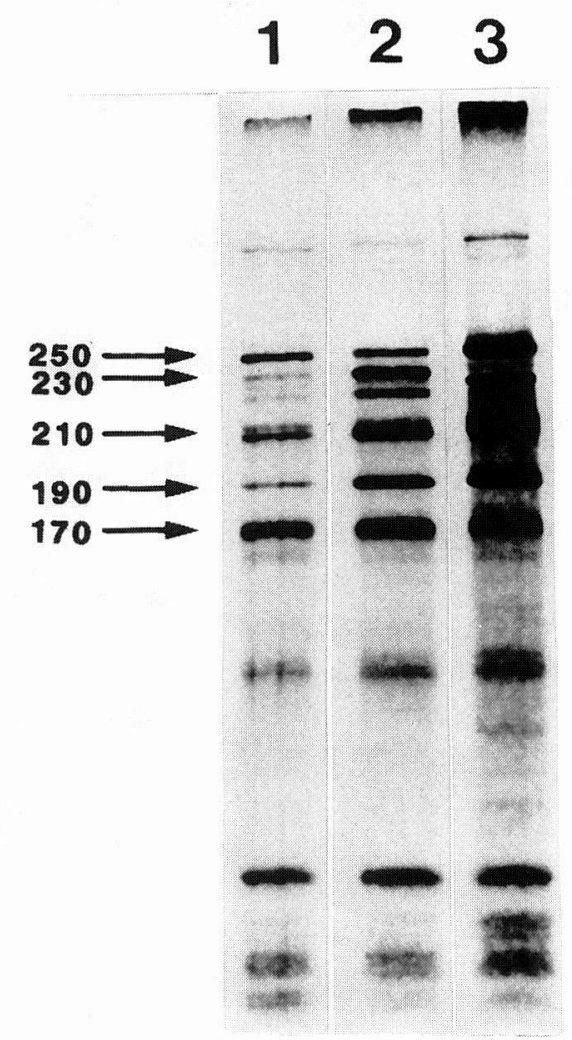

Fig. 3. Immunoprecipitation at high resolution reveals that the $210 \mathrm{kDa}$ PNP antigen is a doublet. Three PNP sera reacted with the $250 \mathrm{kDa}, 230$ $\mathrm{kDa}, 210 \mathrm{kDa}, 190 \mathrm{kDa}$, and $170 \mathrm{kDa}$ proteins, the positions of which are indicated. The $210 \mathrm{kDa}$ protein band was resolved as doublet, shown particularly clearly in lane 1 . 
a.

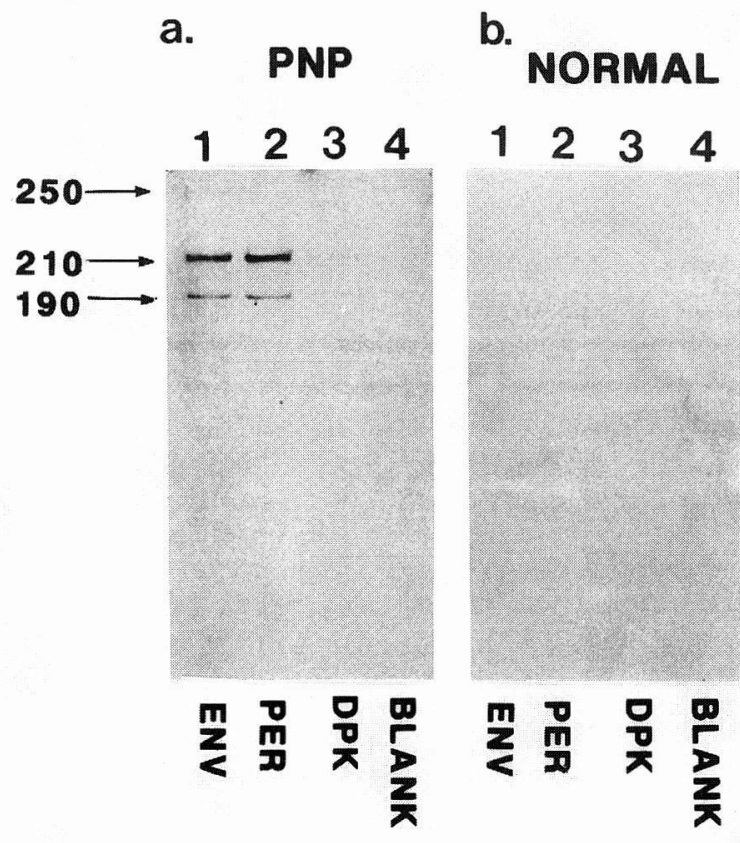

Fig. 4. Combination of immunoprecipitation and immunoblotting indicates that PNP sera react with envoplakin and periplakin. a: Samples immunoprecipitated from extracts of non-radiolabeled keratinocyte with an anti-envoplakin antibody (lane 1), an anti-periplakin (lane 2), an anti-desmoplakin antibody (lane 3) and no antibody (lane 4) were immunoblotted with a representative PNP serum. Both the $210 \mathrm{kDa}$ and 190 $\mathrm{kDa}$ proteins were detected in lanes 1 and 2, but not in lanes 3 and 4 . Faint bands of the $250 \mathrm{kDa}$ and $210 \mathrm{kDa}$ desmoplakins $\mathrm{I} / \mathrm{II}$ were detected in lane 3, although they are not clear in this figure. $\mathbf{b}$ : After stripping, the same blot was immunostained with a representative normal serum, but no specific reactivity was seen. The positions of the $250 \mathrm{kDa}$, $210 \mathrm{kDa}$ and $190 \mathrm{kDa}$ proteins are indicated.

U.K. While envoplakin and periplakin antibodies are known to co-immunoprecipitate a complex of envoplakin and periplakin, these complexes do not contain desmoplakin [29]. Consistent with these observations, 4 of the 6 PNP sera reacted strongly with both the $210 \mathrm{kDa}$ and $190 \mathrm{kDa}$ proteins in the samples immunoprecipitated with antibodies specific for either envoplakin or periplakin (the result of a representative serum is shown in Fig. 4a, lanes 1 and 2 ), but only weakly with desmoplakins I/II in the sample immunoprecipitated with the anti-desmoplakin antibody (Fig. 4a, lane 3). Two PNP sera did not show clear reactivity with the $210 \mathrm{kDa}$ and 190 $\mathrm{kDa}$ proteins, probably due to the low titer of the autoantibodies in these sera.

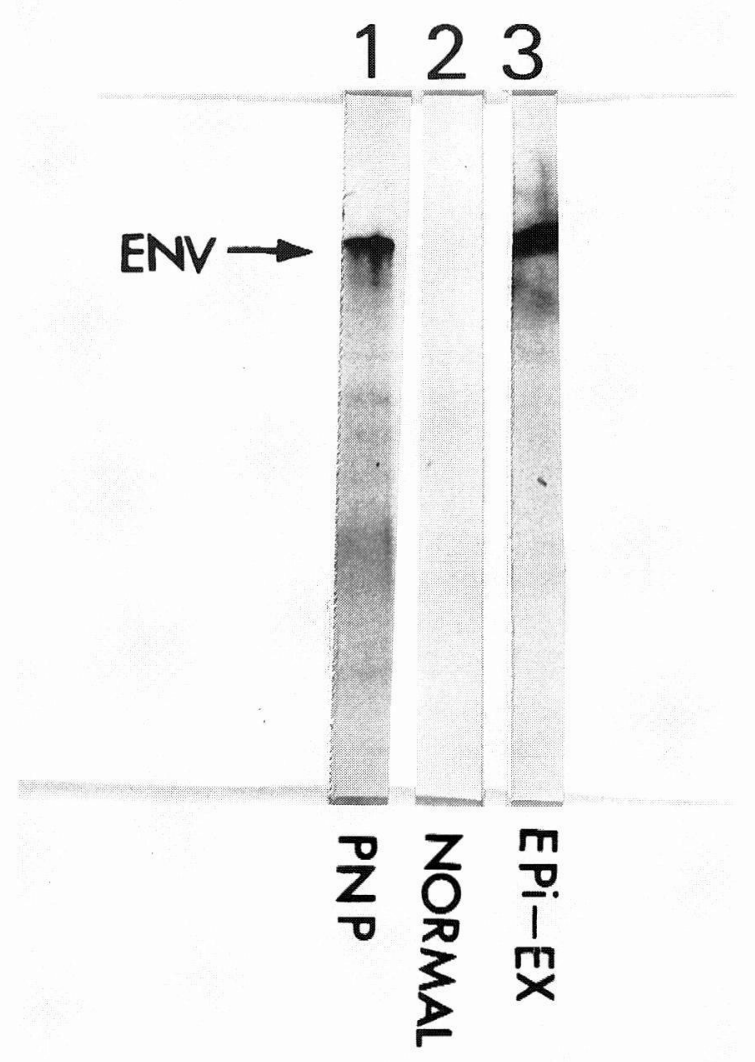

Fig. 5. Reciprocal combination of immunoprecipitation and immunoblotting confirms that envoplakin is identical to the $210 \mathrm{kDa}$ PNP antigen. Samples immunoprecipitated from epidermal extracts with two representative PNP sera (lane 1 and data not shown) or normal serum (lane 2), as well as non-immunoprecipitated epidermal extracts (lane 3), were blotted onto nitrocellulose membranes. An antienvoplakin antibody detected envoplakin only in lane 1, but not in lane 2. Envoplakin was also detected in epidermal extracts (lane 3). The position of envoplakin (ENV) is indicated.

As a negative control, a sample was incubated with protein A sepharose, but no primary antibody (Fig. 4a; lane 4). None of the 8 control pemphigus vulgaris sera and two normal control sera showed any specific reactivity (the result of a representative normal serum is shown in Fig. 4b).

To further confirm that the $210 \mathrm{kDa}$ and $190 \mathrm{kDa}$ PNP antigens are identical to envoplakin and periplakin, protein extracts of normal epidermis were first immunoprecipitated with representative 3 PNP sera or 2 normal control sera, and then immunoblotted with antibodies specific for envoplakin or periplakin (Figs 5 and 6). As expected, envoplakin was present in samples immunoprecipitated with PNP sera, but not in samples immunoprecipitated 


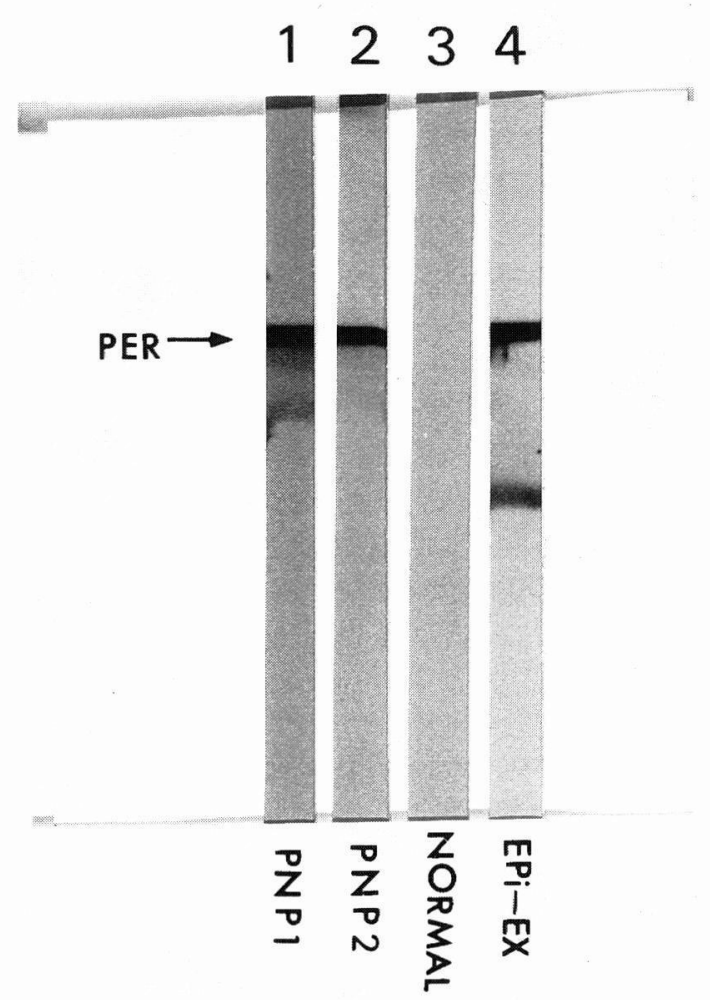

Fig. 6. Reciprocal combination of immunoprecipitation and immunoblotting confirms that periplakin is identical to the $190 \mathrm{kDa}$ PNP antigen. Anti-periplakin antibody detected periplakin in samples immunoprecipitated with the PNP sera (lanes 1 and 2) but not in a sample immunoprecipitated with the normal serum (lane 3). Periplakin was also detected with anti-periplakin antibody in the epidermal extracts (lane 4). The position of periplakin (PER) is indicated.

with normal sera (Fig 5, lanes 1,2 and data not shown). Similarly, an antibody specific for periplakin detected the $190 \mathrm{kDa}$ protein in samples immunoprecipitated with the PNP sera but not in samples immunoprecipitated with normal sera (Fig 6, lanes 13 , and data not shown). As an additional control, epidermal extracts were transferred to nitrocellulose membrane without prior immunoprecipitation and probed with anti-envoplakin or periplakin antibodies, and protein bands of expected size were detected (Fig. 5, lane 3 and Fig. 6, lane 4).

\section{DISCUSSION}

Previous studies have demonstrated that PNP autoantibodies immunoprecipitate a complex profile of high molecular weight proteins in extracts prepared from cultured epidermal keratinocytes. The identity of several of these antigens has been report- ed, but others have not been identified. In particular, the identity of autoantigens in the $210 \mathrm{kDa}$ range has been questioned.

In this study, using immunoblotting of epidermal extracts and antibodies specific to envoplakin and periplakin, we first found that the electrophoretic mobility of envoplakin and periplakin was the same as the $210 \mathrm{kDa}$ and $190 \mathrm{kDa}$ PNP antigens, respectively. The $210 \mathrm{kDa}$ desmoplakin II detected by an anti-desmoplakin antibody migrated slightly more slowly than envoplakin.

Furthermore, immunoprecipitation of metabolically labeled keratinocytes also demonstrated that the $210 \mathrm{kDa}$ and $190 \mathrm{kDa}$ PNP antigens showed the same migration on the gels as envoplakin and periplakin co-immunoprecipitated with the anti-envoplakin antibody. In addition, careful observation of immunoprecipitates of radiolabeled keratinocytes showed that the $210 \mathrm{kDa}$ protein detected by PNP sera consists of a doublet of desmoplakin II and envoplakin.

To confirm that these proteins are indeed recognized by PNP sera, we performed sequential immunoprecipitation followed by immunoblotting. PNP sera detected both envoplakin and periplakin in samples immunoprecipitated with antibodies specific for either envoplakin and periplakin, indicating PNP sera do react with envoplakin and periplakin. This also confirms the finding of Ruhrberg et al. (1997) [29] that envoplakin and periplakin co-immunoprecipitate and may form heterodimers. In the reciprocal experiment, anti-envoplakin and anti-periplakin antibodies detected envoplakin and periplakin, respectively, in samples immunoprecipitated with PNP sera, further indicating that envoplakin and periplakin are indeed PNP antigens.

These results establish that both envoplakin and periplakin are components of the PNP antigen complex. This further supports the previous result by Kim et al. that immunoscreening a keratinocyte cDNA library with a PNP serum cloned a partial cDNA corresponding to envoplakin [30]. Joly et al. showed that PNP sera react with a $185 \mathrm{kDa}$ protein that co-migrates with the protein detected by a human IgM monoclonal antibody F12 [33], which has been established from lymphocytes of a pemphigus vulgaris patient [34], and it will be interesting to determine whether F12 reacts with periplakin.

We previously showed that, while most PNP sera immunoprecipitate the $250 \mathrm{kDa}, 230 \mathrm{kDa}, 210 \mathrm{kDa}$, $190 \mathrm{kDa}$ and $170 \mathrm{kDa}$ proteins in various patterns, most PNP sera detect only the $210 \mathrm{kDa}$ and $190 \mathrm{kDa}$ proteins using immunoblotting of human epidermal 
extracts [17]. One possibility is that PNP sera bind directly only to envoplakin and periplakin, and that the other proteins are co-precipitated as part of a protein complex. This, however, seems unlikely, because the present study and that of Ruhrberg et al. [29] indicated that, although envoplakin and periplakin form a protein complex, desmoplakins I/II and BP230 are not immunoprecipitated with antibodies to envoplakin or periplakin. Furthermore, a subset of PNP sera do detect either desmoplakins I/II or BP230 as well as envoplakin and periplakin by immunoblotting, even though the majority of PNP sera react only with the two proteins. These results strongly suggest that most PNP sera contain multiple autoantibodies that independently recognize each PNP antigen. It now seems more likely that PNP patients produce antibodies against linear epitopes on envoplakin and periplakin, whereas epitopes on desmoplakins I/II and BP230 are conformationallydependent.

It is surprising that all the known PNP antigens belong to the plakin family. Although the reason why PNP patients preferentially produce autoantibodies against plakin family proteins is not clear at the present, it seems possible that a particularly immunogenic sequence motif in the structure may be common in this protein family. Alternatively, socalled epitope-spreading mechanism [35] might induce antibodies to plakin family spread from other antigens, which are adjacent to plakin family proteins. In this respect, it is interesting to note that bullous pemphigoid patients detect BP230 very frequently [36] and produce higher titer antibodies against cytoplasmic BP230 than BP180, which is a transmembranous protein and is considered to be more important in the pathogenecity.

Because all the plakin family proteins have a cytoplasmic location, the antigens are presumably inaccessible to autoantibodies in intact cells. Therefore, there may be pathogenic antibodies to other transmembranous protein(s) which play(s) an initial role in the pathogenesis of PNP, i.e., causing blistering. One candidate is the $170 \mathrm{kDa}$ protein which is frequently detected by PNP sera. In addition, previous studies using immunoblotting [17] indicated that Dsg3 is detected by some PNP sera, suggesting that pemphigus vulgaris antigen is also involved in the pathogenesis of PNP. Finally, it has recently been reported that all the 25 PNP sera showed IgG antiDsg3 antibodies and 16 of the 25 PNP sera reacted with Dsg1 in a specific ELISA using recombinant Dsg1 and Dsg3 [37]. However, it might be agreed that, once the keratinocyte membrane is disrupted by the antibodies against transmembrane protein(s), antibodies against plakin family are induced and enter into the cells, causing the characteristic lesions of PNP. Future studies to identify pathogenic antigens will be necessary for further understanding the pathomechanisms of the skin and mucosal lesions of PNP.

ACKNOWLEDGMENTS: The author is grateful to Prof. T. Hashimoto, Department of Dermatology, Kurume University School of Medicine, Fukuoka, Japan for encouraging during this study and the critical reading of this manuscript, and Dr. David R. Garrod, Manchester University, Manchester, U.K. for providing the anti-desmoplakin mouse monoclonal antibody (11-5F). The author also wishes to gratefully acknowledge Dr. Chritiana Ruhrberg and Dr. Fiona M. Watt, Keratinocyte Laboratory, London, U.K., Dr. Kathleen J. Green, Departments of Pathology and Dermatology, the R.H. Lurie Cancer Center, North-western University Medical School, Chicago, U.S.A., and Dr. Grant J. Anhalt, Department of Dermatology, Johns Hopkins University School of Medicine, Baltimore, U.S.A. for various supports for this study. This work was supported by a Grant-in-Aid for Scientific Research from the Ministry of Education, Science and Culture of Japan, a gramt from the Ministry of Health and Welfare of Japan, and a Collaborative Research Project of the British Council, Tokyo, Japarn.

\section{REFERENCES}

1. Stanley JR, Yaar M, Hawley-Nelson P, and Katz SI. Pemphigus antibodies identify a cell surface glycoprotein synthesized by human and mouse keratinocytes. J Clin Invest 1982; 70:281-288.

2. Stanley JR. Pemphigus and pemphigoid as paradigm of organ-specific, autoantibody-mediated diseases. J Clin Invest 1989; 83:1443-1448.

3. Hashimoto T, Ogawa MM, Konohana A, and Nishikawa T. Detection of pemphigus vulgaris and pemphigus foliaceus antigens by immunoblot analysis using different antigen sources. J Invest Dermatol 1990; 94:327-331.

4. Koch PJ, Walsh MJ, Schmelz M, Goldschmidt MD, Zimbelmann $\mathrm{R}$ et al. Identification of desmoglein, a constitutive desmosomal glycoprotein, as a member of the cadherin family of cell adhesion molecules. Eur J Cell Biol 1990; 53:1-12.

5. Amagai M, Klaus-Kovtun V, and Stanley JR. Autoantibodies against a novel epithelial cadherin in pemphigus vulgaris, a disease of cell adhesion. Cell 1991; 67:869-877.

6. Amagai M, Hashimoto T, Shimizu N, and Nishikawa T. Absorption of pathogenic autoantibodies by the extracellular domain of pemphigus vulgaris antigen (Dsg3) produced by baculovirus. J Clin Invest 1994; 94:59-67.

7. Anhalt GJ, Kim S-C, Stanley JR, Korman NJ, Jabs DA et al. An autoimmune mucocutaneous disease associated with neoplasia. N Engl J Med 1990; 323:1729-1735.

8. Horn TD, and Anhalt GJ. Histologic features of paraneo- 
plastic pemphigus. Arch Dermatol 1992; 128:1091-1095.

9. Oursler JR, Labib RS, Ariss-Abdo L, Burke T, O'Keefe EJ et al. Human autoantibodies against desmoplakins in paraneoplastic pemphigus. J Clin Invest 1992; 89:17751782.

10. Fullerton SH, Woodley DT, Smoller BR, and Anhalt GJ. Paraneoplastic pemphigus with autoantibody deposition in bronchial epithelium after autologous bone marrow transplantation. JAMA 1992; 267:1500-1502.

11. Camisa C, Helm TN, Liu YC, Valenzuela R, Allen C et al. Paraneoplastic pemphigus: A report of three cases including one long-term survivor. J Am Acad Dermatol 1992; 27:547-553.

12. Camisa C, and Helm TN. Paraneoplastic pemphigus is a distinct neoplasia-induced autoimmune disease. Arch Dermatol 1993; 129:883-886.

13. Bystryn J-C, Hodak E, Gao S-Q, Chuba JV, and Amorosi EL. A paraneoplastic mixed bullous skin disease associated with anti-skin antibodies and a B-cell lymphoma. Arch Dermatol 1993; 129:870-875.

14. Stevens SR, Griffiths CEM, Anhalt GJ, and Cooper KD. Paraneoplastic pemphigus presenting as a lichen planus pemphigoides-like eruption. Arch Dermatol 1993; 129:866-869.

15. Rybojad M, Leblanc T, Flageul B, Bernard PH, Morel P et al. Paraneoplastic pemphigus in a child with a T-cell lymphoblastic 1 ymphoma. Br J Dermatol 1993; 128:418422.

16. Stevens HP, Ostlere LS, Black MM, Nishikawa T, Hashimoto $\mathrm{T}$ et al. Paraneoplastic pemphigus as a presenting feature of an occult lymphoma. Eur J Dermatol 1994; 4:26-29.

17. Hashimoto T, Amagai M, Watanabe K, Chorzelski PT, Bhogal BS et al. Characterization of paraneoplastic pemphigus autoantigens by immunoblot analysis. J Invest Dermatol 1995; 104:829-834.

18. Green KJ, Parry DAD, Steinert PM, Virata MLA, Wagner RM et al. Structure of the human desmoplakins. Implications for function in the desmosomal plaque. J Biol Chem 1990; 265:2603-2612.

19. Sun TT, and Green H. Differentiation of the epidermal keratinocyte in cell culture: formation of the cornified envelope. Cell 1976; 9:511-521.

20. Reichert U, Michel S, and Schmidt R. The cornified envelope: a key structure of terminally differentiating keratinocytes. In: Molecular Biology of the Skin, ed. Darmon $\mathrm{M}$ and Blumenberg M, Academic Press, Inc, San Diego, pp 107-150, 1993.

21. Simon M. The epidermal cornified envelope and its precursors. In: The Keratinocyte Handbook, ed. Leigh IM, Lane EB and Watt FM, Cambridge University Press, Cambridge, pp 275-292, 1994.

22. Steinert PM, and Marekov LN. The proteins elafin, filaggrin, keratin intermediate filaments, loricrin, and small proline-rich proteins 1 and 2 are isodipeptide crosslinked components of the human epidermal cornified cell envelope. J Biol Chem 1995; 270:17702-17711.

23. Steinert PM, and Marekov LN. Direct evidence that involucrin is a major early isopeptide cross-linked component of the keratinocyte cornified cell envelope. J Biol
Chem 1997; 272:2021-2030.

24. Robinson NA, Lapic S, Welter JF, and Eckert RL. S100 A11, S100 A10, annexin, desmosomal proteins, small proline-rich proteins, plasminogen activator inhibitor- 2 and involucrin are components of the cornified envelope of cultured human epidermal keratinocytes. J Biol Chem $1997 ; 272: 12035-12046$.

25. Simon M, and Green H. Participation of membraneassociated proteins in the formation of the cross-linked envelope of the keratinocyte. Cell 1984; 36:827-834.

26. Green KJ, Virata ML, Elgart GW, Stanley JR, and Parry DAD. Comparative structural analysis of desmoplakin, bullous pemphigoid antigen and plectin: members of a new gene family involved in organization of intermediate filaments. Int J Biol Macromol 1992; 14:145-153.

27. Ruhrberg C, and Watt FM. The plakin family: versatile organizers of cytoskeletal architecture. Curr Opin Genet Dev 1997; 7:392-397.

28. Ruhrberg C, Hajibagheri N, Simon M, Dooley TP, and Watt FM. Envoplakin, a novel precursor of the cornified envelope that has homology to desmoplakin. J Cell Biol 1996; 134:715-729.

29. Ruhrberg C, Hajibagheri N, Parry DAD, and Watt FM. Periplakin, a novel component of cornified envelopes and desmosomes that belongs to the plakin family and forms complexes with envoplakin. J Cell Biol 1997; 139:18351849.

30. Kim S-C, Kwon YD, and Lee IJx. cDNA cloning of the $210 \mathrm{kDa}$ paraneoplastic pemphigus antigen reveals that envoplakin is a component of the antigen complex. J Invest Dermatol 1997; 109:365-369.

31. Sugi $T$, Hashimoto $T$, Hibi $T$, and Nishikawa $T$. Production of human monoclonal anti-basement membrane zone (BMZ) antibodies from a patient with bullous pemphigoid (BP) by Epstein-Barr virus transformation. Analyses of the heterogeneity of anti-BMZ antibodies in BP sera using them. J Clin Invest 1989; 84:1050-1055.

32. Ebihara T, Hashimoto T, Kudoh J, Gamou S, Shimizu N et al. Detection of the $170-\mathrm{kDa}$ bullous pemphigoid antigen by immunoprecipitation. J Invest Dermatol 1993; 100:176-179.

33. Joly P, Thomine E, Gilbert D, Verdier S, Delpech A et al. Overlapping distribution of autoantibody specificities in paraneoplastic pemphigus and pemphigus vulgaris. J Invest Dermatol 1994; 103:65-72.

34. Gilbert D, Joly P, Jouen F, Thibout A, Delpech A et al. Production of a human monoclonal anti-epithelial cell surface antibody derived from a patient with pemphigus vulgaris. J Autoimmun 1992; 5:173-182.

35. Vanderlugt CJ, and Miller SD. Epitope spreading. Curr Opin Immunol 1996; 8:831-836.

36. Stanley JR, Hawley-Nelson P, Yuspa SH, Shevach EM, and Katz SI. Characterization of bullous pemphigoid antigen: A unique basement membrane protein of stratified squamous epithelia. Cell 1981; 24:897-903.

37. Amagai M, Nishikawa T, Anhalt GJ, and Hashimoto T. Antibodies against desmoglein 3 (pemphigus vulgaris antigen) are present in sera from patients with paraneoplastic pemphigus and cause acantholysis in vivo in neonatal mice. J Clin Invest 1998; 102:775-782. 